\title{
Operating Conditions of Hollow Fiber Supported Liquid Membrane for Phenol Extraction from Coal Gasification Wastewater
}

\author{
Yao Jie, ${ }^{1,}$, Cai Chao ${ }^{1}$, Zhang Dandan ${ }^{1}$, Guo Hongxia ${ }^{2}$, You Hong ${ }^{1}$, Han Bangjun ${ }^{3}$, \\ Han Yahong ${ }^{1}$, Du Ziwei ${ }^{4}$, Yang Shuren ${ }^{1}$, Sjack van Agtmaal ${ }^{5}$ and Feng Chunhui ${ }^{5}$ \\ ${ }^{1}$ School of Municipal and Environmental Engineering, Harbin Institute of Technology, P. R. China \\ ${ }^{2}$ Henan Mechanical \& Electrical Engineering College, Xinxiang, Henan, P.R. China \\ ${ }^{3}$ School of Civil Engineering, Heilongjiang University, Xuefu Road, Harbin150090, P.R. China \\ ${ }^{4}$ China Overseas Property Co., Ltd. (Yantai), P.R. China \\ ${ }^{5}$ Evides Industriewater B.V. Schaardijk 150, 3063 NH Rotterdam, the Netherlands
}

\begin{abstract}
The extraction and recycling of phenol from high concentration coal gasification wastewater has been studied using polypropylene (PP) hollow fiber membrane and polyvinylidene fluoride (PVDF) hollow fiber membrane as liquid membrane support, the mixture of tributyl phosphate (TBP) and kerosene as liquid membrane phase, and sodium hydroxide as stripping agent in the process of extraction. The experiments investigated the effect of the operating conditions of the hollow fiber supported liquid membrane, such as aqueous phase temperature and the connection forms of membrane modules, on the extraction efficiency of phenol from high concentration coal gasification wastewater. The conclusions obtained from lab scale experiments provided guidance for scale-up experiments. So, in the scale-up experiments, three membrane modules connected in parallel, then three membrane modules connected in series were used to increase the treatment capacity and improve the treatment effect, under the operating conditions of wastewater temperature $20{ }^{\circ} \mathrm{C}, \mathrm{PH} 7.5 \sim 8.1$, flow rate $100 \mathrm{~L} / \mathrm{h}$ and the concentration of stripping phase $0.1 \mathrm{~mol} / \mathrm{L}$, stripping phase flow rate $50 \mathrm{~L} / \mathrm{h}$, the extraction efficiency of the PP-TBP supported liquid membrane system was $87.02 \%$ and the phenol concentration of effluent was $218.14 \mathrm{mg} / \mathrm{L}$. And the phenol concentration of effluent met the requirements of further biodegradation treatment.
\end{abstract}

Keywords: Coal gasification wastewater, Extraction efficiency, Hollow fiber membrane, Scale-up experiments.

\section{INTRODUCTION}

In recent years, supported liquid membrane technology has been widely studied for the separation and concentration of varieties of compounds, such as heavy metal ions, organics and gases [1-4]. In this technique, a hydrophobic porous polymeric membrane holds the membrane liquid which generally contains membrane solvent and carrier into its micro-pores by capillary action, to separate the feed phase and stripping phase [5]. The technique is a combination of three simultaneously occurring processes: molecules or ions extraction from the feed phase to the membrane support, diffusion through the membrane support and re-extraction to the stripping phase [6].

Supported liquid membrane extraction technique has many advantages, such as small extract agent usage, high extraction efficiency, low running costs and no secondary pollution [7]. Apart from the above advantages, hollow fiber supported liquid membrane with large mass transfer area per unit volume and good stability is one of the most suitable technologies for

*Address correspondence to this author at the School of Municipal and Environmental Engineering, Harbin Institute of Technology, Harbin150091, P. R. China; Tel: 0086-13904501245; E-mail: yaojiejiehit@163.com separation industry. The operating conditions are the important factors for high extraction efficiency of the supported liquid membrane [8]. So, the study of the operating conditions can provide basic guaranty for economical and efficient operation of supported liquid membrane extraction process [9]. Compared to hollow fiber supported liquid membrane, the studies about flat supported liquid membrane are much more [10-12]. Therefore, in order to know more about hollow fiber supported liquid membrane technology and make the technology applicable for industrial production, it is extremely necessary to investigate the effect of the operating conditions of the hollow fiber supported liquid membrane on extraction efficiency of phenol from high concentration coal gasification wastewater, including wastewater temperature, $\mathrm{pH}$, flow rate, stripping phase concentration, and the connection forms of membrane modules.

Tributyl phosphate (TBP) is the most popular solvating reagent, used for many years in the processing of recovery of phenol. The liquid-liquid extraction of phenol with mixture of TBP and hexane, 2-octanol, or kerosene has been studied by Zidi et al., they found TBP-kerosene system performed best, so the mixture of TBP and kerosene was used as liquid 
membrane phase in their following experiments [8]. Also, our previous studies have found that the supported liquid membrane system performed most effectively when the volume proportion of TBP was $20 \%$ in TBP-kerosene mixture [13]. So, in this paper, the mixture of TBP and kerosene was used as liquid membrane phase. In the practical application, the connections of membrane modules are necessary for increasing the treatment capacity or effect, and the temperature of actual coal chemical wastewater is higher than room temperature. So, in order to know more about the effect of the operating conditions of hollow fiber supported liquid membrane, the effect of the connection forms of membrane modules and feed phase temperatures has been investigated.

\section{EXPERIMENTAL}

\subsection{Experimental Materials and Equipments}

Tributyl phosphate (98\%, Shanghai LaiYashi Chemical Co., Ltd.); trialkyl phosphine oxide (93\%, Shanghai LaiYashi Chemical Co., Ltd.); analytical grade kerosene and sodium hydroxide; magnetic stirrer (Jintan Shuangjie Instruments Plant); GC-MS (Model: 6890 (GC)/5975 (MS), Agilent); T6-UV-Vis spectrophotometer (Beijing Puxi General Instrument Co., Ltd.); peristaltic pump (Model: BT100-2J, Baoding Lange Constant Flow Pump Co., Ltd.) are used.

The parameters of membrane module in the lab scale experiments are outer diameter $4.0 \mathrm{~cm}$, effective length $21 \mathrm{~cm}$, packing density $20 \%$, effective mass transfer area of $0.28 \mathrm{~m}^{2}$, and that of membrane module in the scale-up experiments: outer diameter $9.0 \mathrm{~cm}$, effective length $60 \mathrm{~cm}$, effective mass transfer area of 2 $\mathrm{m}^{2}$. And fiber parameters are shown in Table 1 (The modules include hollow fiber membranes produced by themselves were purchased from Institute of Biological and Chemistry, Tianjin Polytechnic University).

The wastewater, with COD $13000-15000 \mathrm{mg} / \mathrm{L}$; total phenols 1600-1800 mg/L; pH 7.5-8.6, from Qitaihe Baotailong Coal to Chemical Co., Ltd, was analyzed with GC-MS, pretreated by bromide derivatization, then extracted by methyl tertiary butyl ether, shown in Figure 1. GC-MS spectra reveals that components of coal gas wastewater includes phenol, binary phenols (catechol, resorcinol, hydroquinone), methyl phenol ( $p$-methyl phenol, m-cresol, o-cresol), multiple diphenol methyl (2- methyl-1, 3-dihydroxybenzene, 3,4-dimethylphenol, 2,3,5-trimethylphenol, 4,5-dimethyl-, 3-dihydroxybenzene, 3-methyl-1,2-dihydroxybenzene), etc.

\subsection{Transport Experiments Procedure}

Flow chart of supported liquid membrane extraction to treat coal gasification wastewater was illustrated in Figure 2.

Before the start of experiment, in order to form liquid membrane phase in membrane pores which plays an dominant role in extraction process, the liquid membrane phase flowed inside the tube of membrane system for 8-10 minutes. As the experiment was started, aqueous phase flowed in circulation inside the tube of the supported liquid membrane system, and the stripping phase flowed countercurrent in the shell of the supported liquid membrane system at the same time. And different operating variables were selected

Table 1: Parameters of the Hollow Fiber Membrane Materials

\begin{tabular}{|c|c|c|c|c|}
\hline Membrane material & $\begin{array}{c}\text { Diameter } \\
(\mathbf{m m})\end{array}$ & $\begin{array}{c}\text { Thickness } \\
(\mathbf{m m})\end{array}$ & $\begin{array}{c}\text { Open porosity } \\
(\%)\end{array}$ & 85 \\
\hline \hline PVDF & 0.8 & 0.3 & 72 & 0.16 \\
\hline PP & 0.4 & 0.1 & 0.1 \\
\hline
\end{tabular}

Table 2: The Operating Conditions of the Membrane Modules in Parallel Experiments

\begin{tabular}{|c|c|c|c|}
\hline Number of membrane modules in parallel & $\begin{array}{c}\text { Volume of aqueous } \\
\text { phase }\end{array}$ & $\begin{array}{c}\text { Flow rate of aqueous } \\
\text { phase }\end{array}$ & $\begin{array}{c}\text { Volume of stripping } \\
\text { phase }\end{array}$ \\
\hline \hline A membrane modules & $1 \mathrm{~L}$ & $5 \mathrm{~L} / \mathrm{h}$ & $0.3 \mathrm{~L}$ \\
\hline Two membrane modules & $2 \mathrm{~L}$ & $10 / \mathrm{h}$ & $0.6 \mathrm{~L}$ \\
\hline Three membrane modules & $3 \mathrm{~L}$ & $15 / \mathrm{h}$ & $0.9 \mathrm{~L}$ \\
\hline
\end{tabular}




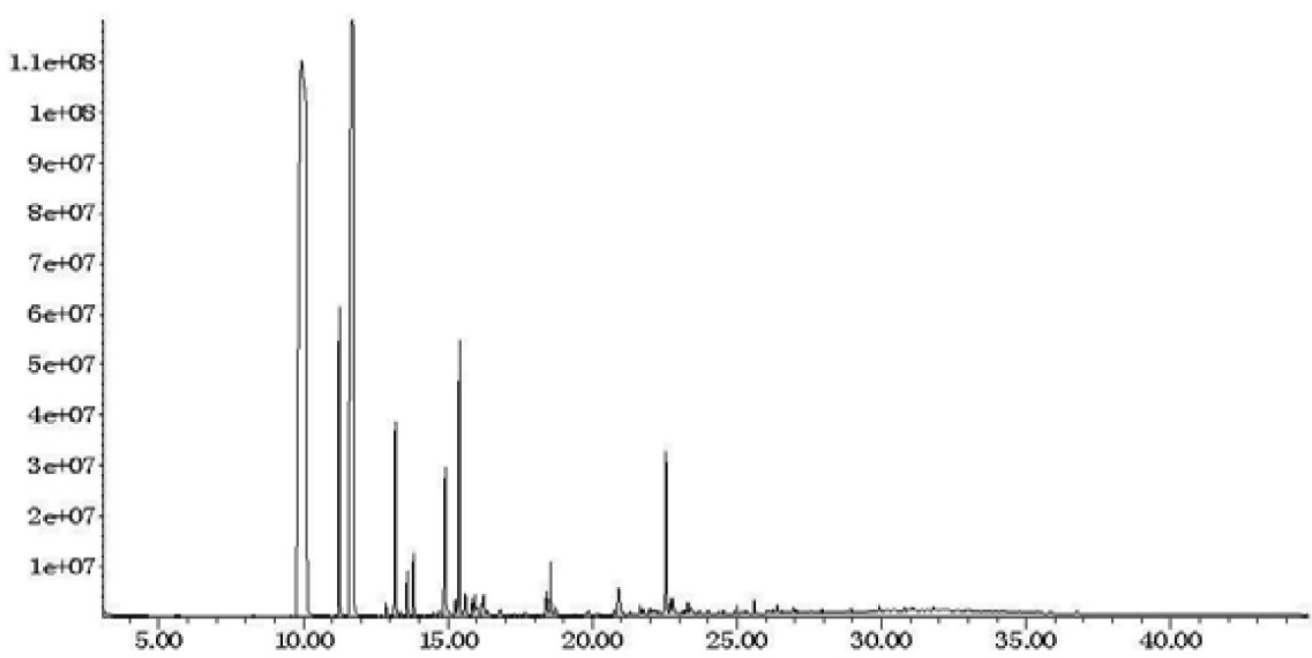

$T$ in $\rightarrow$

Figure 1: The GC-MS spectra of wastewater samples.

according to the experimental objectives. To reduce contaminations on the supported liquid membrane, after the experiments, backwash with deionized water was carried out for ten minutes. And water samples were analyzed using UV-visible spectrophotometry, pretreated 4-amino antipyrine at the wavelength of 510 $\mathrm{nm}$.

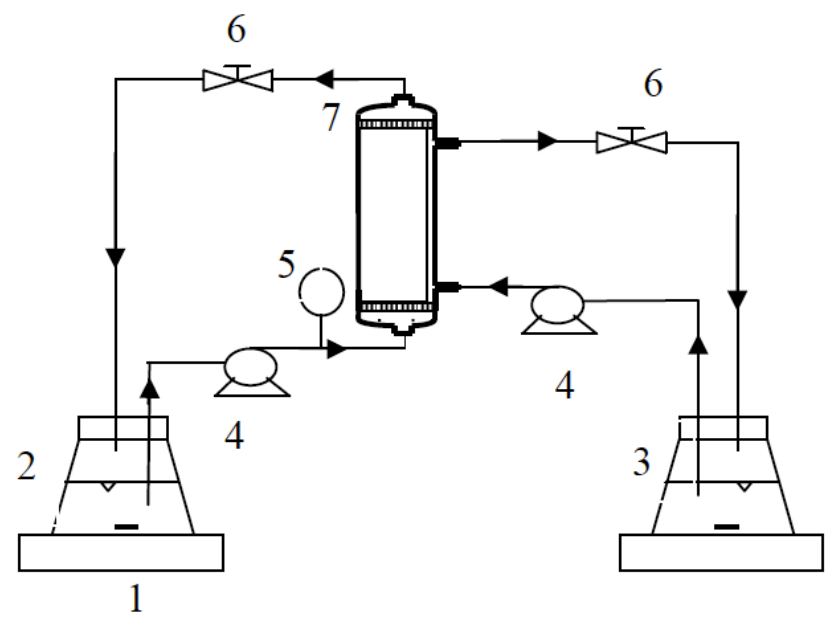

Figure 2: Flow chart of supported liquid membrane extraction to treat coal gasification wastewater.

1 -Stirrer; 2 -Feed tank; 3-NaOH solvent tank; 4 -Peristaltic pump; 5 -Gauges; 6 -Valves; 7-supported liquid membrane module.

\subsection{Theoretical}

The relationship between the mass transfer coefficient $k_{w}$ in feed phase and the effective length of the membrane modules can be expressed by the formula (1) [14]

$$
k_{w}=\frac{1.62 D_{w}}{d_{i n}}\left(\frac{d_{i n}^{2} u_{w}}{L D_{w}}\right)^{\frac{1}{3}}
$$

In which: $k_{\mathrm{w}}$ : the mass transfer coefficient in feed phase, $\mathrm{m} / \mathrm{s}$;

$D_{\mathrm{w}}$ : diffusion coefficient of phenols in the feed phase, $\mathrm{m}^{2} / \mathrm{s}$;

$d_{i n}$ : the inner diameter of the hollow fiber membrane, $\mathrm{m}$;

$L$ : the effective length of the membrane modules, m;

$u_{\mathrm{w}}$ : the feed phase flow rate, $\mathrm{m} / \mathrm{s}$.

Increasing the effective length of the membrane module will make the value of $k_{w}$ decrease which means that the mass transfer efficiency of supported liquid membrane system will decline under the same operating conditions. Therefore, it is necessary to increase the value of $k_{w}$ without increasing the effective length of the membrane module. And the same hollow fiber membrane modules connected in series can increase the effective mass transfer area without increasing the effective length of the membrane module.

M.J. Costello [15] studied shell flow state of the hollow fiber membrane under different conditions of packing densities and found that increasing the packing density of the hollow fiber membrane module, the pressure drop would increase at the same flow rate. 
The packing density of hollow fiber membrane module $\Phi$ had a considerable impact on the mass transfer coefficient of the hollow fiber membrane module, and the experiments got the empirical formula (2):

$\mathrm{Sh}=(0.53-0.58 \Phi) \mathrm{Re}^{0.53} \mathrm{Sc}^{0.33}$

From equation (2), the packing density of hollow fiber membrane module $\Phi$ has a strong negative influence on the mass transfer coefficient of the membrane module. So, the effective mass transfer area of the hollow fiber membrane module has mutually contradictory relationship with the mass transfer coefficient. Therefore, it is necessary to improve the hollow fiber membrane module mass transfer area without increasing the packing density of the membrane module. The hollow fiber membrane modules in parallel can be a good solution to this problem.

\section{RESULTS AND DISCUSSION}

\subsection{Effect of Membrane Modules Connected in Series on Extraction Efficiency}

In this section, the same size hollow fiber membrane modules were used in the experiments which tested the effect of the membrane modules in series on extraction efficiency of phenol from coal gasification wastewater.

The flow rate of aqueous phase and stripping phase were fixed at $5 \mathrm{~L} / \mathrm{h}, 0.1 \mathrm{~mol} / \mathrm{L} \mathrm{NaOH}$ as stripping phase, aqueous phase volume $V a q=1.0 \mathrm{~L}$, and stripping phase volume $V_{R}=0.3 \mathrm{~L}$, with kerosene and TBP (volume proportion of $20 \%$ ) as liquid membrane phase,

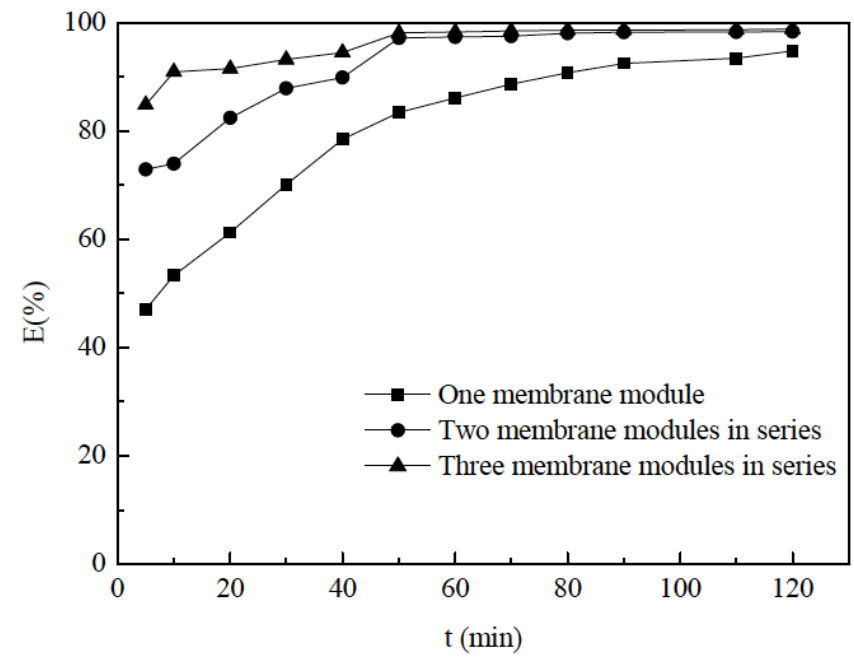

Figure 3: The effect of PP membrane modules in series on the extraction. and PP membrane in the experiments. The results were shown in Figure 3, with the increase of the number of the membrane modules in series, the time to reach the equilibrium was shortened and the extraction efficiency was improved significantly.

The system reached the extraction equilibrium at $50 \mathrm{~min}$ and the extraction efficiency was $98.1 \%$ under the condition of three membrane modules connected in series. Compared to three membrane modules connected in series, the system with two membrane modules connected in series given the same extraction efficiency after reaching extraction equilibrium. Thus, the membrane modules connected in series could enhance the extraction efficiency of the supported liquid membrane system and shorten the time to reach extraction equilibrium. However, increasing the number of the membrane modules connected in series would increase the mass transfer resistance which means that energy consumption would be increased. Therefore, the largest number of the membrane modules connected in series was fixed at 3 in the experiments.

In the same extraction conditions, the same experiments with PVDF membrane modules were conducted and the results were shown in Figure 4.

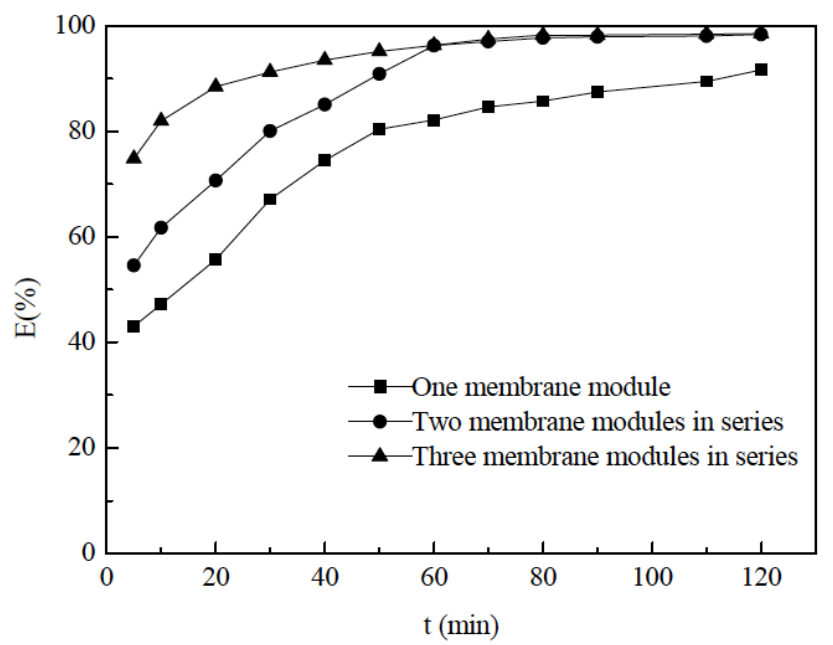

Figure 4: The effect of PVDF membrane modules in series on the extraction efficiency.

Figure 4 showed that the conclusions got from Figure $\mathbf{3}$ also applied to PVDF membrane and supported liquid membrane system with the membrane modules connected in series was significantly better than only one supported liquid membrane module in the final extraction efficiency and the time taken by reaching extraction equilibrium. Therefore, the membrane modules connected in series was an 
important way to strengthen the effectiveness of supported liquid membrane system without increasing the effective length of the membrane module. Taking into account the energy consumption, two membrane modules connected in series would be used in the scale-up experiments.

\subsection{Effect of the Membrane Modules in Parallel on the Extraction Efficiency}

The operating conditions were the flow rate of stripping phase $5 \mathrm{~L} / \mathrm{h}, 0.1 \mathrm{~mol} / \mathrm{L} \mathrm{NaOH}$ as stripping phase, and stripping phase volume $V_{R}=0.3 \mathrm{~L}$. Other operating conditions of the membrane modules in parallel experiments were shown in Tab.2, with kerosene and TBP (volume proportion of $20 \%$ ) as liquid membrane phase, the PP membrane modules used in the experiments, shown in Figure $\mathbf{5}$.

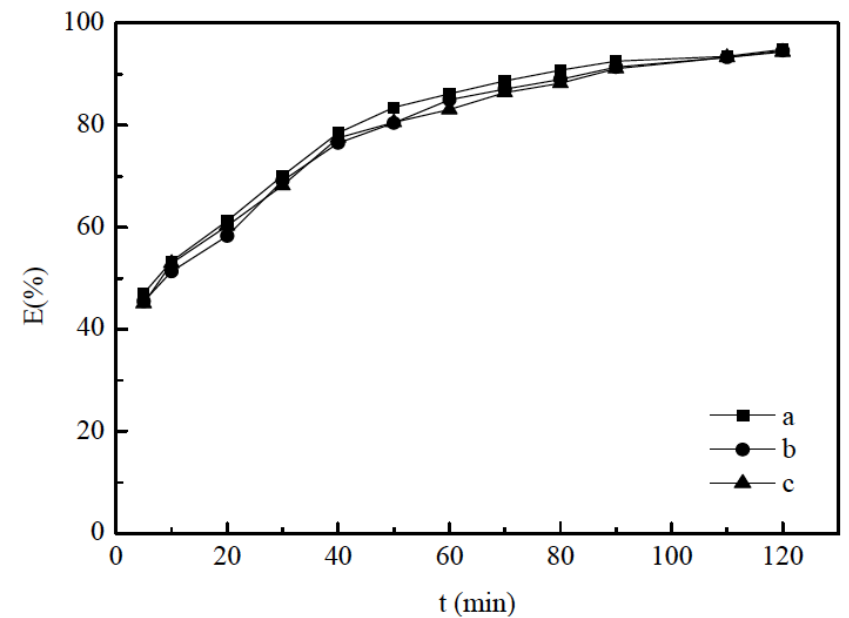

Figure 5: The effect of PP membrane modules in parallel on the extraction, (a) one membrane module, feed volume:1L, flow rate:5L/h; (b) two membrane modules in parallel, feed volume:2L, flow rate:10L/h; (c) three membrane modules in parallel, feed volume:3L, flow rate:15L/h.

As shown in the Figure $\mathbf{5}$, the experiment results meet the theoretical prediction, and membrane modules in parallel can increase the water treatment capacity of the supported liquid membrane system. We can see that, when $3 \mathrm{~L}$ aqueous phase was treated by the system with three membrane modules connected in parallel, the almost same extraction efficiency was got compared to that $1 \mathrm{~L}$ aqueous phase was treated by one membrane module in the same time. Therefore, the membrane modules connected in parallel could effectively increase the water treatment capacity.

As the volume of the aqueous phase was constant $1 \mathrm{~L}$ and the aqueous phase flow rate changed with the increase of the number of the membrane modules connected in parallel, the same experiments on the PP membrane modules were conducted, and the results were shown in Figure 6.

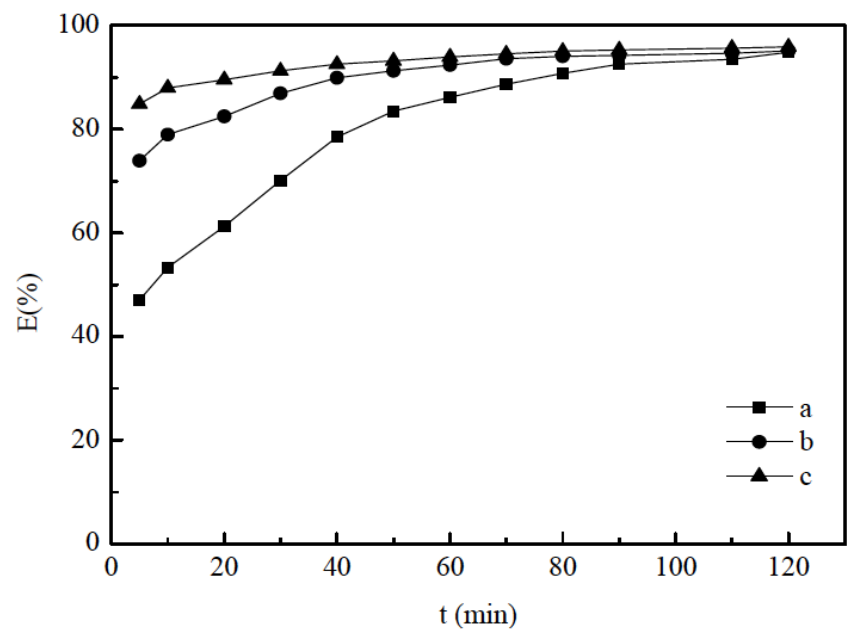

Figure 6: The effect of PP membrane modules in parallel on the extraction, (a) one membrane module, feed volume:1L, flow rate:5L/h; (b) two membrane modules in parallel, feed volume:1L, flow rate: $10 \mathrm{~L} / \mathrm{h}$; (c) three membrane modules in parallel, feed volume: $1 \mathrm{~L}$, flow rate:15L/h.

From Figure 6, without changing the volume of the aqueous phase, the supported liquid membrane system with two or three membrane modules in parallel, compared to one membrane module system, could quickly reach extraction equilibrium, but the final extraction efficiency of all the systems appeared limited different.

So, the above two sets of experiments showed that the hollow fiber membrane modules connected in parallel could improve the effective mass transfer area without increasing the membrane module packing densities and enhance the wastewater treatment capacity per unit time. Therefore, the subsequent scale-up experiments will adopt the connection form of membrane modules in parallel to enhance the wastewater treatment capacity.

\subsection{Effect of the Aqueous Phase Temperature on the Extraction Efficiency}

Increasing aqueous phase temperature can improve the mass transfer rate of phenol in the aqueous phase. Taking into account the factors and make full use of the waste heat, the experiments testing the effect of the feed phase temperature on the extraction efficiency have been carried out.

The operating conditions were the flow rate of aqueous phase and stripping phase $5 \mathrm{~L} / \mathrm{h}, 0.1 \mathrm{~mol} / \mathrm{L}$ 
$\mathrm{NaOH}$ as stripping phase, aqueous phase volume Vaq $=1.0 \mathrm{~L}$, and stripping phase volume $V_{R}=0.3 \mathrm{~L}$. The changes of phenol concentrations in the aqueous phase were detected, with kerosene and TBP (volume proportion of $20 \%$ ) as liquid membrane phase, the PP membrane, and the results being shown in Figure 7.

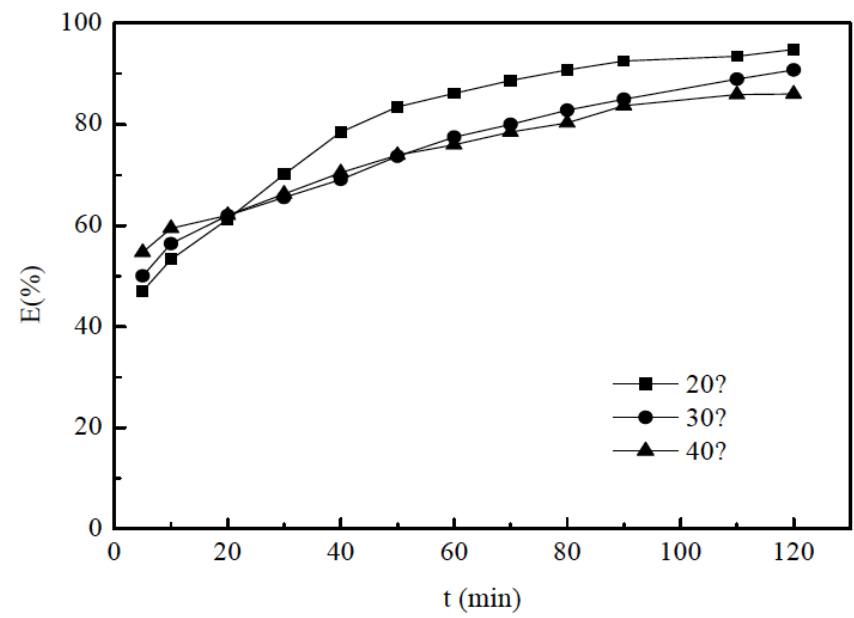

Figure 7: The effect of aqueous phase temperature on PP membrane modules extraction efficiency.

From Figure 7, compared to the aqueous phase temperature at $20{ }^{\circ} \mathrm{C}$, the extraction efficiency of supported liquid membrane system with the aqueous phase temperature at $40{ }^{\circ} \mathrm{C}$ was higher at the beginning, but in the $20 \mathrm{~min}$, both of the systems had a same extraction efficiency, and then its extraction efficiency became less than the system with the aqueous phase temperature at $20{ }^{\circ} \mathrm{C}$. The system with the aqueous phase temperature at $30{ }^{\circ} \mathrm{C}$ also showed a similar trend.

The extraction ability of TBP for phenolic substances will decrease with the increase of aqueous phase temperature since the temperature increase will reduce the viscosity of liquid membrane phase which makes liquid membrane phase more easily lost and reduces the stability of supported liquid membrane system.

To exclude the impact of the membrane material, under the same operating conditions, the same experiments on PVDF membrane modules were conducted and the results were shown in Figure 8.

From Figure 8, the experiments with PVDF membrane modules further validated the conclusion that the extraction efficiency would be reduced with the increase of the aqueous phase temperature. Therefore, the aqueous phase temperature was fixed at $20^{\circ} \mathrm{C}$ in the scale-up experiments.

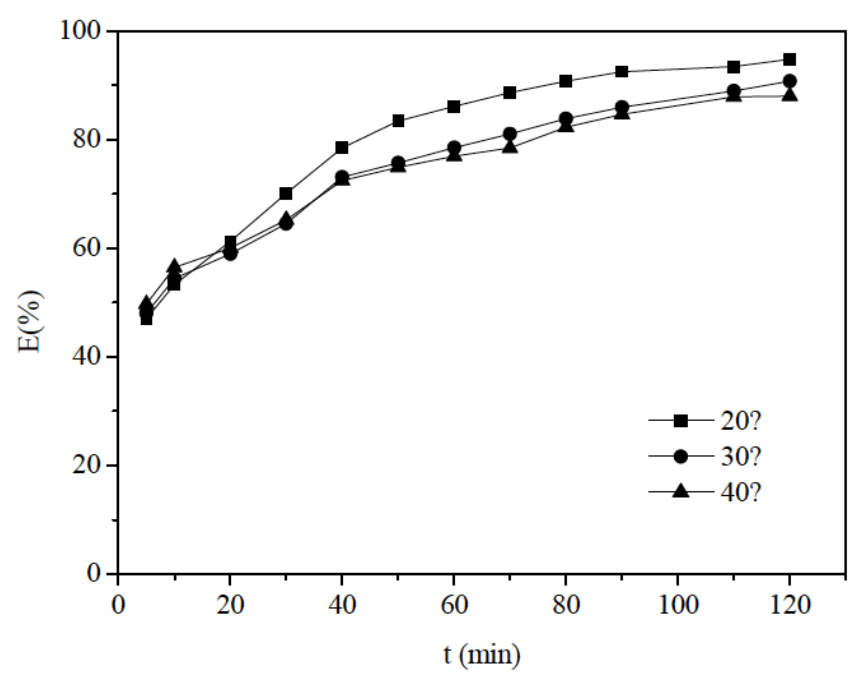

Figure 8: The effect of aqueous phase temperature on PVDF membrane modules extraction.

\subsection{Effect of Membrane Modules Connection form on the Extraction Efficiency in Scale-Up Experiments}

To verify the conclusions obtained from lab scale experiments, the scale-up experiments were carried out with the same working principles of the lab scale experimental apparatus, but the wastewater treatment capacity of the scale-up experimental devices was $150 \mathrm{~L}$ per experiment.

The operating conditions were the flow rate of aqueous phase $100 \mathrm{~L} / \mathrm{h}$, aqueous phase volume $\mathrm{Vaq}=$ $150 \mathrm{~L}$ and $0.1 \mathrm{~mol} / \mathrm{L} \mathrm{NaOH}$ as stripping phase, the flow rate of stripping phase $50 \mathrm{~L} / \mathrm{h}$, stripping phase volume $V_{R}=0.3 \mathrm{~L}$, with kerosene and TBP (volume proportion of $20 \%$ ) as liquid membrane phase, 3 PVDF membrane modules connected in parallel, then 3 PVDF membrane modules connected in series, the results being shown in Figure 9.

As is shown in the Figure 9, the extraction efficiency could be improved with the increase of the number of membrane modules connected in series. The extraction efficiency of the PVDF membrane modules in series for coal gasification wastewater was $82.36 \%$ and the phenol concentration of effluent was $312.77 \mathrm{mg} / \mathrm{L}$ after the device running for five hours.

To further verify the effect of the membrane modules connected in series on the extraction efficiency in the scale-up experiments, under the same operating conditions, with kerosene and TBP (volume proportion of $20 \%$ ) as liquid membrane phase, experiments with 3 PP membrane modules connected in parallel and then 3 PP membrane modules 


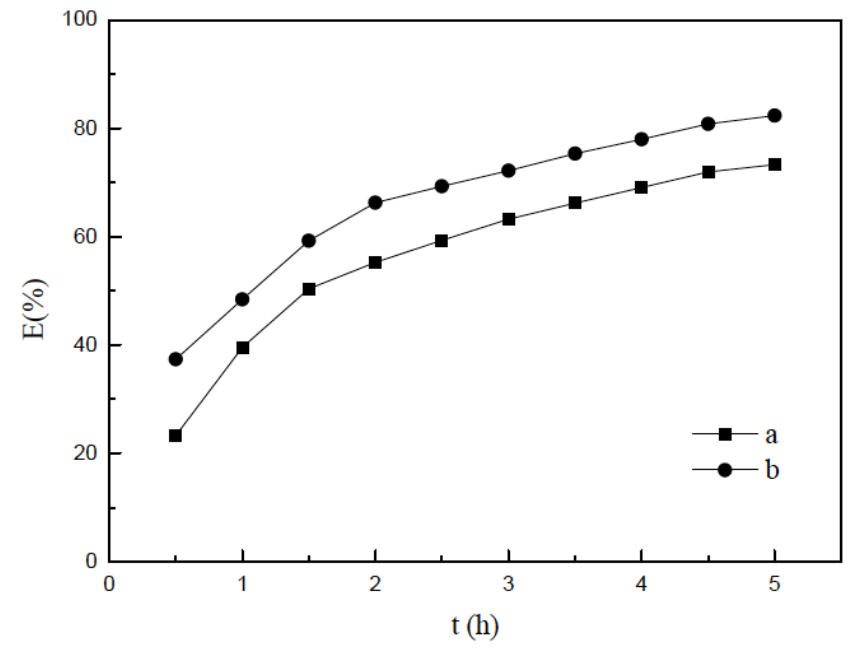

Figure 9: The effect of PVDF membrane modules in series on the extraction efficiency in scale-up experiments: (a) only three PVDF membrane modules connected in parallel; (b) three PVDF membrane modules connected in parallel and then three PVDF membrane modules connected in series.

connected in series were carried out, the results being given in Figure 10.

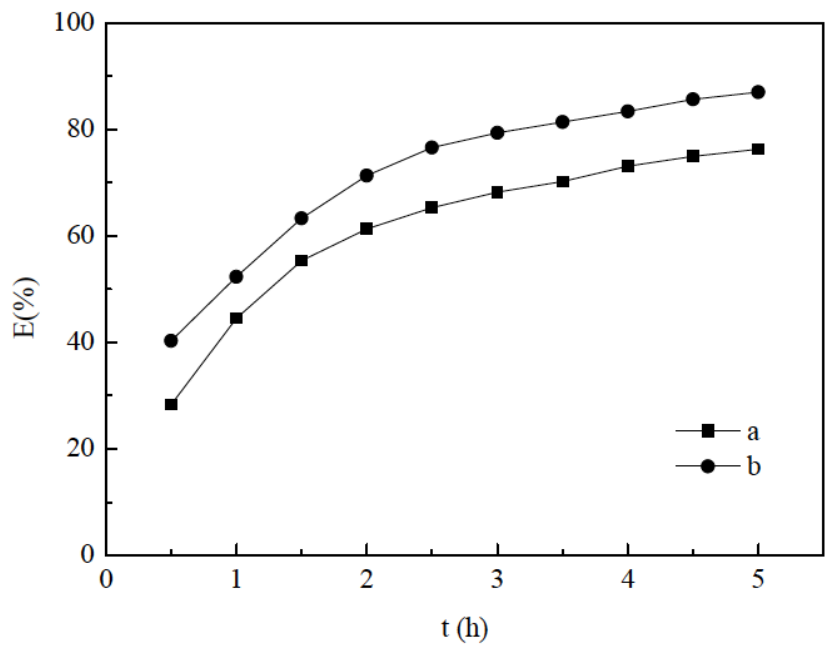

Figure 10: The effect of PP membrane modules in series on the extraction efficiency in scale-up experiments: (a) only three PP membrane modules connected in parallel; (b) three PP membrane modules connected in parallel and then three PP membrane modules connected in series.

From Figure 10, it is found that the extraction efficiency of supported liquid membrane system for high concentration coal gasification wastewater containing phenol could not achieve the desired results, when only three membrane modules in parallel were used. With the increase of the number of membrane modules in series, the extraction efficiency of supported liquid membrane system was significantly improved. The extraction efficiency of the PP membrane modules in series was $87.02 \%$ and the phenol concentration of effluent was $218.14 \mathrm{mg} / \mathrm{L}$ after operation for five hours. Although the effect of the membrane modules in series on the extraction process in scale-up experiments was not so obvious compared to lab scale experiments, the extraction efficiency of the supported liquid membrane system with the membrane modules connected in series was satisfactory and the phenol concentration of effluent was $218.14 \mathrm{mg} / \mathrm{L}$, biodegradable for further treatment.

\section{CONCLUSION}

Following conclusions could be obtained through the above extraction experiments for coal gasification wastewater containing phenol. First, with the increase of the number of the membrane modules connected in series, the time to reach the equilibrium was shortened and the extraction efficiency of the supported liquid membrane system improved significantly. Secondly, the membrane modules connected in parallel could increase the water treatment capacity of the hollow fiber supported liquid membrane system. Thirdly, the extraction efficiency of supported liquid membrane system with $20 \%$ TBP-kerosene as liquid membrane phase would decrease as the aqueous phase temperature increasing. And finally, the conclusions obtained in the lab scale experiments equally applied to the scale-up experiments. The phenol concentration of effluent of the supported liquid membrane system with membrane modules connected in series met the requirements of further biodegradation after the scaleup experimental devices running for five hours.

\section{REFERENCES}

[1] Reyes-Aguilera JA, Gonzalez MP, Navarro R, Saucedo TI, Avila-Rodriguez M. Supported liquid membranes (SLM) for recovery of bismuth from aqueous solutions. J Membr Sci 2008; 310(1): 13-19. http://dx.doi.org/10.1016/i.memsci.2007.10.020

[2] Kazemi P, Peydayesh M, Bandegi A, Mohammadi T, Bakhtiari O. Stability and extraction study of phenolic wastewater treatment by supported liquid membrane using tributyl phosphate and sesame oil as liquid membrane. Chem Eng Res Design 2014; 92(2): 375-83. http://dx.doi.org/10.1016/j.cherd.2013.07.023

[3] Nosrati S, Jayakumar NS, Hashim MA. Performance evaluation of supported ionic liquid membrane for removal of phenol[J]. J Hazardous Mater 2011; 192(3): 1283-90. http://dx.doi.org/10.1016/j.jhazmat.2011.06.037

[4] Lan W, Li S, Xu J, et al. Preparation and Carbon Dioxide Separation Performance of a Hollow Fiber Supported Ionic Liquid Membrane. Ind Eng Chem Res 2013; 52(20): 6770-77. http://dx.doi.org/10.1021/ie3034152

[5] Kocherginsky NM, Yang Q, Seelam L. Recent advances in supported liquid membrane technology. Separat Purificat Technol 2007; 53(2): 171-77. http://dx.doi.org/10.1016/i.seppur.2006.06.022 
[6] Lozano LJ, Godinez C, De Los Rios AP, et al. Recent advances in supported ionic liquid membrane technology. J Membr Sci 2011; 376(1): 1-14. http://dx.doi.org/10.1016/j.memsci.2011.03.036

[7] Yang XJ, Fane AG, Soldenhoff K. Comparison of liquid membrane processes for metal separations: permeability, stability, and selectivity. Ind Eng Chem Res 2003; 42(2): 392403. http://dx.doi.org/10.1021/ie011044z

[8] Zidi C, Tayeb R, Ali MBS, et al. Liquid-liquid extraction and transport across supported liquid membrane of phenol using tributyl phosphate. J Membr Sci 2010; 360(1): 334-40. http://dx.doi.org/10.1016/j.memsci.2010.05.027

[9] Jie $\mathrm{Y}$, Zhi-ru H, An-guo L, et al. Supported liquid membrane extraction to treat coal gasification wastewater containing high concentrations phenol. J Harbin Inst Tech 2012; 19(1). http://d.wanfangdata.com.cn/periodical_hebgydxxbe201201011.aspx

[10] Venkateswaran P, Palanivelu K. Recovery of phenol from aqueous solution by supported liquid membrane using vegetable oils as liquid membrane. J Hazardous Mater 2006; 131(1): 146-52.

http://dx.doi.org/10.1016/j.jhazmat.2005.09.025
[11] Zidi C, Tayeb R, Dhahbi M. Extraction of phenol from aqueous solutions by means of supported liquid membrane (MLS) containing tri-<i> n</i>-octyl phosphine oxide (TOPO). J Hazardous Mater 2011; 194: 62-68. http://dx.doi.org/10.1016/j.jhazmat.2011.07.071

[12] Zheng HD, Wang BY, Wu YX, et al. Instability mechanisms of supported liquid membranes for copper (II) ion extraction [J]. Colloids and Surfaces A: Physicochemical and Engineering Aspects 2009; 351(1): 38-45. http://dx.doi.org/10.1016/j.colsurfa.2009.09.028

[13] Jie $Y$, Ziwei D, Hong $Y$, et al. The Effect of Supported Liquid Membrane and Liquid Membrane Phase on the Extraction Efficiency of Coal Gasification Wastewater. J Membr Separat Technol 2013; 2: 191-97. http://lifescienceglobal.com/pms/ index.php/jmst/article/view/1221

[14] Youyuan D, Xiuli W, Jiading $W$. The research on the mass transfer characteristics of membrane extraction process. J Chem Eng Chin Univer 1991; 5(2): 87-93. http://www.cnki. com.cn/Article/CJFD1991-GXHX199102000.htm

[15] Costello M, Fane A, Hogan $P$, et al. The effect of shell side hydrodynamics on the performance of axial flow hollow fiber modules. J Membr Sci 1993; 80(1): 1-11. http://dx.doi.org/10.1016/0376-7388(93)85127-I

\section{DOI: http://dx.doi.org/10.6000/1929-6037.2014.03.02.5}

(C) 2014 Jie et al.; Licensee Lifescience Global.

This is an open access article licensed under the terms of the Creative Commons Attribution Non-Commercial License (http://creativecommons.org/licenses/by-nc/3.0/) which permits unrestricted, non-commercial use, distribution and reproduction in any medium, provided the work is properly cited. 